\title{
The Importance of Origins: Why Cognitive Development is Central to a Mature Understanding of Social Cognition
}

\author{
Y. Dunham ${ }^{1, *}$ and K.R. Olson ${ }^{2}$ \\ ${ }^{1}$ Psychological Sciences, University of California, Merced and ${ }^{2}$ Department of Psychology, Yale University, USA
}

\begin{abstract}
The overwhelming majority of work in social cognition has focused on adults, what can be called end-state social cognition. We argue that development (and especially cognitive development) can provide a theoretical and methodological tool to advance the study of social cognition. Developmental psychology can offer unique insight into the origin of end-state processes, providing insight into how they develop from simpler components and thus serving as constraints to theoretical models of end-state social cognition. We provide examples of 1) areas where existing developmental research offers potential insight into our understanding of adult processes, 2) areas where new developmental research can directly address theoretical debates in social cognition, and 3) a case study of one successful, extant bridge between development and social cognition. Finally, we comment more generally on both the promise and potential pitfalls of an integrated social-developmental approach to social cognition.
\end{abstract}

\section{INTRODUCTION}

For the past 30 years, social cognition has focused almost exclusively on the social thought, behavior and interactions of adults. While some noted social psychologists have strayed into studies of the development of social cognition [e.g., 1-4], we found that only between $1 \%$ (JESP) and 5\% $(P S P R)$ of the articles published in top social psychology journals involved the study of children or development ${ }^{1}$.

That the development of social cognition is important and interesting is hardly controversial. In addition, the utility of comparing developmental and adult processes has been well-illustrated elsewhere [5,6]. In this paper we would like to make a somewhat stronger and narrower claim: The study of development can not just inform but importantly constrain theories of adult end-state cognition in unique ways, ways which have not been widely appreciated in the social psychological community. In what follows, we first describe the theoretical approach of cognitive development ${ }^{2}$ that we believe can offer the firmest foundation for the study of the development of social cognition. We then provide examples of 1) areas in which large developmental literatures with potential contributions have been largely neglected, 2) how a developmental approach is beginning to be used to help social psychologists differentiate between competing theories, and 3) an area in which a successful integration has already taken place, with great benefit to the field.

\section{Cognitive Development as a Theoretical Approach}

Several core tenets of cognitive development are described below. While these tenets will be familiar to some of our readers, we want to make our theoretical commitments clear, while acknowledging that even within the field of cog-

\footnotetext{
*Address correspondence to this author at the Psychological Sciences, University of California Merced. PO Box 2039, Merced, CA 95344, USA; Tel: 209-225-4549; Fax: 209-228-4007; E-mail: ydunham@ucmerced.edu
}

nitive development, some of what follows will not be entirely uncontroversial.

Cognitive development has its origins in the work of Jean Piaget [7], who revolutionized the study of development through careful case studies of his own children, and erected a theoretical edifice that endures to this day in many areas of developmental psychology. Chief among his conclusions is the observation that the ways in which children learn are not merely error-prone imitations of the ways in which adults learn. Rather, the conceptual systems children bring to bear on learning are often qualitatively different than those employed by adults; the story of development is thus in part the story of conceptual change [8]. For our purposes, the crucial insight is that children may be acquiring knowledge in ways that adults do not, and of course adults have learning strategies and knowledge resources that are unavailable to children. Thus, the acquisition of attitudes and beliefs in adults [9-11] cannot necessarily serve as a model for the ways in which these same constructs develop earlier in the lifespan, because adult acquisition mechanisms may simply be unavailable to children. For example, we may try to create a novel stereotype in adults (e.g., green people are bad mail carriers), and may assume that the ways in which adults come to adopt this stereotype are similar to how they acquired "real" stereotypes (e.g., Blacks are criminals). But the content of most "real" stereotypes is learned in childhood, and thus may be the result of learning mechanisms specific to childhood.

Of course, understanding how adults acquire these beliefs is an interesting question in its own right, but we must acknowledge that children may acquire these same structures in quite different ways, implying that many of the phenomena we care about (e.g., social attitudes and stereotypes) may be uniquely the result of learning processes no longer primary in adults. That is, the structure of end-state social cognition is to a large degree the result of developmental proc- 
esses that may differ in important ways from end-state social cognition itself. Failure to appreciate this point risks producing acquisition theories that are not actually able to explain the phenomena of interest.

The field of cognitive development has also moved beyond Piaget. Many theorists would now argue that at least some mental structures are innate and largely invariant across the lifespan [12,13]. Generally, these 'core knowledge' faculties are thought of as supports for reasoning and knowledge acquisition in certain domains of knowledge; for example, both infants and adults have a core system for estimating how many objects are in a scene [14], as well as a core system for representing and tracking objects [15]. While these systems show some quantitative refinement with age (e.g., becoming more sensitive), the qualitative properties of the systems appear to remain constant over development, and their unique 'signatures' can be found in adults as well as infants. Similar core systems for reasoning about physical objects [12,16] and agency and intentionality [17-19] are present in early infancy, to name just the best documented cases.

While adults and young children share these basic mechanisms (e.g., for computing numerosity), in many of these domains children eventually develop completely new sets of representational capacities that fundamentally change their cognitive capacities. In the case of number, they develop an understanding of the counting principles embodied in the number line and the Arabic numeral system, finally developing the capability of referring to precise numerosities [20]. With these new conceptual resources, children become able to reason about number in a qualitatively different way, using conceptual resources that simply did not exist before (and that do not exist in culture that have not developed the relevant 'technology' of a discrete number system [21]). If such changes are present in social cognitive development, it would mean that learning itself might be characterized by fairly sharp discontinuities: Adult representational capacities may not have been available for young children, and so could not underlie initial acquisition of socially relevant knowledge. For example, in an example we will return to below, children under about age 4 , while understanding mental constructs like desire, and recognizing that humans are goal-directed agents, nonetheless show striking deficits in their ability to reason about more specific mental states like beliefs [22]. Here too, a fairly sharp discontinuity separates young children from adult mentalizers. How might this divide affect the acquisition of early social knowledge? That is, if children are unable to reason about mental states like beliefs, might they draw a very different set of conclusions from observing the actions of others?

Closely related to the considerations above, a second issue arising in cognitive developmental work concerns the importance of understanding the ultimate origin of cognitive phenomena. In cognitive development these questions are usually answered in terms of whether phenomena are innate or learned. For example, the core aspects of numeric understanding just discussed (e.g., adding a set of one object to another set of one object produces a set of two objects) are believed to be innate and shared with non-human primates $[15,23]$, whereas understanding the number line is not only learned but is not present in some human societies [21,24].
This last example is particularly suggestive, as it implies that cultural variation will be found in some but not all areas of human cognition. Meaningful cultural variation is a staple of cross-cultural social psychology; cognitive development both provides a 'roadmap' to those areas in which meaningful variation should and should not be expected, but also provides careful case analyses of how complex social knowledge (such as the representational resources embodied in the number line) actually develops.

Another example will illustrate. It is tempting to take evidence of cultural dissimilarity in adulthood as evidence that there is no innate mechanism involved. Developmental data belies this assumption. Take recent work by Hespos and Spelke [25], focusing on the fact that adults in Korea, but not adults in the U.S. make a linguistic and conceptual distinction between two kinds of containment relations, dividing them into instances of loose fit from instances of tight fit [26]. Studies conducted solely with American and Korean adults would never have settled the question of whether Korean is creating a distinction by lexicalizing a difference, or whether the lack of lexicalization in English is eroding a basic distinction that English speakers would otherwise observe. However, cross-cultural work with infants revealed that both American and Korean infants respect the tightloose fit distinction [25], revealing the initial state and thus demonstrating that, at least in this case, language performs a maintaining rather than a constructing function.

Understanding origins can also shed light on the possibility of interventions. Those areas of cognition that are rooted in innate mechanisms are liable to be extremely resistant to change. For example, it is unlikely that we are going to show much improvement in our ability to estimate dot arrays - this ability appears to be based on a very basic numerical 'accumulator' present in babies and other animals [27]. On the other hand, there have been well-documented successes in helping young and in particular underprivileged children understand the properties of the number line, a skill upon which much of future math success rests [28]. This should not be a surprise: Successful intervention requires understanding the mechanisms from which the end-state derives, and understanding that requires drawing on developmental findings.

In summary, the field of social cognitive development seeks to characterize the mental representations, learning mechanisms, and cognitive processes that lead to the acquisition of social knowledge, and to understand how that social knowledge interacts with the child's behavior. It differs from prior approaches in its focus on learning mechanisms, rather than simply descriptions of the child's state of knowledge, as well as its openness to the possibility that some social knowledge may be supported by or acquired through innate mechanisms specialized for that purpose. We have argued that introducing this perspective to adult social cognition has immediate value, through its ability to inform and constrain theoretical claims. We will now provide examples of how this integration might actually take place.

\section{APPLYING DEVELOPMENT TO SOCIAL COGNI- TION: CASE STUDIES IN INTEGRATION}

Despite the fact that developmental and social psychologists work within the same major field (psychology), are 
housed in the same buildings, and share at least some of their professional journals, granting agencies and major professional organizations, these two fields seldom read one another's research despite the fact that their research areas often overlap substantially (with notable exceptions, e.g., the work of Carol Dweck, Luigi Castelli, and Melanie Killen, to name but a few). Others have pointed out some of the historical and institutional reasons for this divide [6,29], so we will not belabor the point here, and will instead focus on how areas of current research in developmental psychology can influence social cognition ${ }^{3}$.

\section{Integration Waiting to Happen}

Developmental research on theory of mind (ToM) focuses on the child's emerging ability to represent mental states, both his or her own and those of others. While even infants have some skeletal competencies that relate to representations of mental states (e.g., the ability to represent goaldirected behavior [19]), young children show clear deficits in their abilities to represent mental states. ToM research has tended to focus on three sorts of competencies [30]: Appearance-reality distinctions (e.g., understanding that a sponge that looks like a rock is a sponge and not a rock), understanding of false beliefs (e.g., understanding that someone else might entertain an erroneous belief about e.g., the location of a secretly displaced object), and perspective taking abilities (e.g., understanding that other people's visual and psychological vantage points will lead them to construe situations differently).

Why are these studies important for social psychologists to know, especially if children are passing theory of mind tasks by age four, well before social psychologists are likely to study their behavior? Royzman, Cassidy, and Baron [31] explored this question. They discuss how theory of mind errors are similar to and may even be responsible for many of the findings in judgment and decision-making (JDM), a large sub-field of social psychology that focuses on heuristics and biases that affect everyday reasoning. While we will not re-hash all the aspects of their argument here, we will highlight a few that are most relevant for our purposes. Amongst the many JDM biases they believe are related to theory of mind are: the false consensus effect, hindsight bias, the curse of expertise, the illusion of transparency and the curse of knowledge. In many of these biases, the errors occur because the subject has information that he/she needs to ignore in order to correctly simulate the informational state of the other. For example the curse of expertise comes about because of the difficulty in discounting one's own richer body of acquired knowledge in a given domain. Similarly, in the classic false-belief task, one needs to discount the privileged information provided by one's own prior experience, and instead focus on the information the new actor does or does not have. While the false-belief task is of course much simpler, the curse of expertise is plausibly built on many of the same principles, yet adults make consistent errors. Our hope is that researchers studying topics including attribution and JDM will follow the lead of Royzman and colleagues and begin to build their own connections between theory of mind research and their adult work.

One promising example of the integration of developmental theory of mind work and social cognition is a recent paper by Epley, Morewedge, \& Keysar [32], in which they compare children and adults' performance on a perspective taking task. Childhood deficits in perspective taking are widely documented [30], but we might be tempted to assume that they are safely overcome by adulthood. However, Epley and colleagues find that children and adults have a strikingly similar egocentric bias in their initial perspective taking, but that adults subsequently correct for this initial bias. However, when this correction process is interrupted, e.g., by placing adult participants under cognitive load, adult and child performances become remarkably similar. They suggest that egocentric bias is a relatively automatic process that remains stable throughout development, but that as we age, our ability to self-correct increases, allowing us to overcome our egocentrism more rapidly and effortlessly. Merging the adult and child literatures challenges an initial conception of a developmental decline in egocentrism, revealing instead stable egocentrism coupled with the rise of an ever more powerful system of executive control.

Other areas for theoretical integration may come from cognitive developmental work on infants' understanding of agency and intention, as well as children's understanding of folk biology, folk psychology, and essentialism. For example, children's conceptions of folk biology and folk psychology can provide researchers focusing on prejudice and stereotyping with a broader understanding of why adults treat certain kinds of groups (e.g., racial groups) differently than other kinds of groups. Some researchers in cognitive development have suggested that entrenched racial categories are the result of the child's misapplication of the biological concept of species to superficial human phenotypic variation [33,34]; this might explain why some social distinctions so readily acquire such force and resistance to change.

We conclude that there is a great deal of research currently being done in cognitive development that is important for social cognitivists to examine, critique and extend. In our own lab, collaborations between social cognitivists and cognitive developmentalists have consistently led to questions and answers that are interesting across fields, and that we would not have thought of without the cross-fertilization across disciplines (e.g., $[35,36])$.

\section{Integration Under Way}

One specific way in which a cognitive developmental approach can contribute to the field of social cognition is in testing predictions derived from social cognitive theories. Here we focus on the particular developmental claims implied in much of the theory on dual-process models of social cognitive processing. Dual process models of social cognition, in particular of attitudes, stereotypes, goal-attribution, and self-esteem, have become one of the most vibrant areas of adult social cognition research [e.g., 37-40].

While the details and terminology of dual-process accounts of social cognition vary considerably, nearly all models agree as to the basic character of the division. Here we adopt terminology from [39], based on a distinction between 'implicit' and 'explicit' processing. The explicit system is generally conceptualized as serial, effortful, and deliberative processing. By contrast, the implicit system is generally conceptualized as parallel, effortless or even automatic, and un- 
conscious. Implicit evaluations of social stimuli are usually assumed to be the result of a 'slow-learning' associative system [37] culling the environment for statistical regularities that can support later generalizations (e.g., [38-40]). For example, repeated exposure to negative portrayals of AfricanAmericans (e.g., in local crime news) might lead to a negative association with that group which might affect some aspects of behavior, even when explicit attitudes are thoroughly egalitarian. It is important to note that models of this sort are heavily reliant on, and indeed assume, a specific history of learning. That is, they presuppose a rich set of knowledge structures that are presumably acquired experientially, and thus are grounded in the developmental history of the individual. Yet surprisingly little research has specifically examined how long-term knowledge of the relevant kind is acquired (see [41,42] for a partial exception).

Given that a large portion of these knowledge structures were presumably acquired during childhood, we are faced with the possibility that they were acquired by virtue of attentional and conceptual systems specific to the child. If so, implicit processing in adults is in part the consequence of uniquely developmental processes. An interesting, if speculative, possibility is that some of the biases that characterize adult reasoning may be the entrenched sediment of more limited forms of reasoning, the only forms available to young children, which have been encoded by a slow-learning system and are now resistant to change.

Turning to a more specific example, we would argue that central questions about the nature of the implicit system turn on claims about the nature of acquisition. While to our knowledge it has rarely been framed as a serious theoretical disagreement, there seems to be a sizable rift between those who claim the implicit evaluative system is a slow-learned consequence of repeated exposure to environmental stimuli (e.g., [38,39]) and those who see it as an automatically emerging property of classification, and perhaps even an intrinsic feature of all categorization [43]. While the fact that adults can rapidly acquire implicit evaluative biases $[11,44]$ appears to weigh in on the side of the latter claim, for the reasons outlined above the more definitive source of evidence would be the developmental history of implicit evaluations. The 'slow-learned' position predicts developmental change in the strength of implicit evaluations as a direct function of the input, implying variability that can be predicted from age and cultural/environmental factors such as degree of exposure. On the other hand, the "category-based bias' position predicts that as soon as categories are successfully represented, automatic evaluation will also be present, suggesting that children's implicit evaluations should look, at least in many cases, much like adults'.

Ongoing research in our laboratory has taken up this question. Our data favor the latter, category-based bias, model. Studies of implicit race and gender bias in several child populations in both the US and abroad (where histories of exposure would seem to be quite different) have nearly always shown early implicit bias of a magnitude similar to that found in adults [45-48]. More recently, we found a form of implicit race bias in children as young as 3 that remained stable into adulthood [49]. These data are hard to reconcile with the slow-learning model, which would predict the gradual increase in the strength of bias as exposure accumulates over time. Our evidence suggests that at least in the case of social groups, implicit evaluations are not simply the consequence of a particular history of exposure, and may be a more basic feature of the cognitive systems involved with categorization. Of course, this is not to deny the clear importance of socially-learned information. But from the perspective of cognitive development, our goal is to specify the particular mechanisms that underlie different aspects of knowledge acquisition; to the extent that social biases are acquired simply as a byproduct of categorization, there is no need to postulate a particular learning history. In the case of implicit social attitudes, our evidence supports the notion that implicit attitudes form automatically once social groups are represented, and are affected by social information only modestly, over sustained periods of developmental time.

To summarize, adult theories of social cognition often make clear developmental predictions. Testing these predictions, particularly in cases in which there is theoretical dispute, can bring a powerful source of evidence to bear on the debate. In short, we must first clearly specify the implicit or explicit developmental predictions derivable from a theoretical perspective. Then, using developmental research methodologies, we design experiments to put the predictions to the test. Of course, there are always challenges in specifying these claims with enough precision to empirically test them, but that challenge is no different from the ones researchers face every day, closer to home. We urge that this approach, if taken up with care, can enrich and test theoretical claims and potentially resolve theoretical oppositions.

Other promising avenues flow out of cultural psychology. Culturally mediated differences in cognitive processes by definition rely on histories of social learning, yet these histories are rarely studied directly. Are the sorts of differences in, e.g., the cultural construction of the self identified by East-West researchers [50,51], relatively late emerging? Do they slowly diverge over development or is there a sudden reorganization of knowledge? And what is the direction of change over development, e.g., are infants and young children more like Eastern or Western adults? Again, we bring back the work of Hespos and Spelke [25] as an example. It was only by testing infants that the authors were able to discover that what we see as a difference between Korean and American adults (Koreans distinguish between loose and tight fits, whereas Americans do not) emerges from a similarity in infancy (both groups distinguish loose and tight fitting objects), and that it is the American population which loses a conceptual distinction present in infancy. Similar findings might await a developmental inquiry into cultural psychological findings.

\section{Integration Completed}

Thus far we have laid out how the theoretical and methodological approach of cognitive development can be applied to the study of social cognition. Now, we move to firmer terrain to provide an example of how the boundaries between social cognition and developmental psychology have been successfully negotiated to further our understanding of social cognitive development.

Emotion research, like research on understanding the mental states of others, is a topic that has been studied by both social and developmental psychologists. What makes 
this topic different is that these researchers have long made and tested developmental predictions, and routinely engage in cross-disciplinary discussion and debate [52-57].

From early on, developmental claims have been central to the discussion of emotion. One of the most prominent discussions in the field has centered on defining and understanding distinctions between classes of emotions. Over several decades Paul Ekman and colleagues have established a distinction between what they call basic emotions and other affective phenomena. Ekman [52] created a list of 11 criteria distinguishing basic emotions from other emotions, with one being a "distinctive appearance developmentally." This developmental requirement has become so widely embraced by the social psychological community that now researchers hoping to add new emotions to the list of basic emotions use developmental evidence as a major piece of their argument (e.g., the case of pride; [58]).

Emotion researchers not only claim that emotion capabilities appear in childhood but that particular aspects of emotion are innate $[52,55,57]$. To support this claim of innateness, emotion researchers, like researchers in cognitive development (e.g., [13]), demonstrate that very young infants have emotion concepts. For example, Izard and colleagues have demonstrated that children as young as 2.5 months express interest, joy, sadness and anger [59]. Additionally, Field and colleagues show that neonates under 2 days old are able to discriminate and imitate happy, sad and surprised facial expressions [60].

In large part due to the general agreement on the importance of developmental research to the study of emotion, researchers in that sub-field have been able to make more specific predictions, beyond the claim that aspects of emotion are innate. Now, researchers have moved on to argue exactly which aspects of emotion are innate, thus directly engaging the question of innate versus acquired cognition. Additionally, researchers generate arguments about why emotion was adaptive evolutionarily, and when exactly emotion capabilities appear in development. For example, Izard [57] argues that "if [emotional] expressions are anything, they are a functional communication system that preceded language in evolution and that precedes language in ontogeny" (p.290). Such an argument makes the very specific prediction that young infants should have the capacity for emotional expressions before they can speak, a prediction that can and has been tested by looking at the basic social cognitive abilities of pre-linguistic infants [55].

Of course, we cannot say exactly where the study of emotion would be without the impact of developmental research. However, the category of basic emotions and the sharp distinctions between innate and acquired aspects of emotion and other non-affective phenomena can only have arisen in the context of this cross-disciplinary approach. Thus it is clear that the study of emotion has benefited from understanding its development. Emotion researchers have provided a great example for the rest of the field of how the traditionally rigid boundaries of social and developmental psychology can be crossed to create a more thorough understanding of social cognition. We hope that this provides some evidence that developmental research can fruitfully be integrated into the study of adult social cognition, and that in so doing new light will be shed on the phenomena we already study.

\section{A Word of Caution}

Along with our endorsement of developmental approaches must come a word of caution. Adopting a developmental perspective is not as simple as 'dumbing-down' adult measures for use with children, or atheoretically seeking replications of adult findings with children. As in the best examples we have discussed here, a fruitful integration requires generating theoretically motivated questions, and then developing measures which are appropriate for children of the relevant age. For example, in a research area close to the authors' hearts, trying to understand the development of implicit attitudes in children, we cannot just simplify reaction time measures such as the Implicit Association Test (IAT [61]). A simplified IAT can be used for children as young as 5 or 6 years of age $(45,48)$, but the methodology in inappropriate for younger children both because of its inherent difficulty and our limited understanding of reaction time data in these age ranges. This necessitates the development of new measures that can be shown to tap the same underlying constructs, but which are age-appropriate for younger children and ideally can themselves be used across the lifespan to produce continuity of measurement (see [49] for an example). This is not a trivial methodological problem, but it is one that can yield to our experimental ingenuity just as other such problems have in the past.

\section{CONCLUSIONS}

Throughout this paper we argue that by focusing almost exclusively on adults, social psychology has focused on the end-state of what we see as a long and interesting continuum of development. While this end-state is extremely important and much has and will be gained from focusing on it, we believe it is only part of the full story of social cognition. Work in the area of social cognitive development, work that examines how phenomena emerge and change over time, and the ways in which the 'steady state' of adult psychology is the outcome of developmental changes, can greatly enrich our understanding of social cognition. As more developmental research is conducted, we believe we will find more and more ways in which development constrains and enriches adult social psychological theories.

In this paper we described how developmental psychology, and especially cognitive development, can be used as a theoretical framework and a methodological approach to inform the study of social cognition. In the best cases, it provides a 'proving ground' within which conflicting predictions can be tested and new insight garnered. As in any area of psychology, developmental inquiry requires its own specialized approaches and methods. However, we would encourage a closer look across the disciplinary boundary, and, for the more adventurous, collaboration or cautious forays into the developmental world. We have argued here that this activity is not merely interesting, it is essential to the health of a mature science. While we acknowledge that interdisciplinarity can make for strained marriages, we would argue that social cognition and cognitive development are both close enough to make crosstalk smooth and distant enough to have a have much to teach one another. We look forward to 
the future discoveries that will inevitably result from such partnerships.

\section{NOTES}

1. We performed a PsycInfo search on February 27, 2006 in which we searched for the number of articles containing the keywords "Child*" (to include articles with child or children) or "Development" in articles published between 1970 and 2006 in the journals: Journal of Personality and Social Psychology, Journal of Experimental Social Psychology, Personality and Social Psychology Bulletin, Personality and Social Psychology Review, Social Cognition, British Journal of Social Psychology, and the European Journal of Social Psychology. We found 495 articles with one of those keywords, out of 15,118 published articles (3.27\%). We assume this slightly overestimates the actual number of articles as many articles use the word "development" to refer to studies in which adults develop, for example, new attitudes. If we just include articles with the keyword "child*", the number of articles decreases to 222 or $1.5 \%$.

2. The reader may wonder why we propose the integration of social cognition with cognitive development rather than social development. This decision was a deliberate one, for several reasons. The most important reason has to do with shared theoretical commitments of social cognition and cognitive development that are not traditionally embraced by social developmentalists. Namely, the central role and importance of cognition in influencing behavior is taken for granted in social cognition and cognitive development but has largely been ignored in the field of social development, which has focused more centrally on contextual factors. There have recently been moves within the field of social development to embrace the role of cognition and mental representation [62] and insofar as the role of cognition is adopted, we believe that our argument here becomes relevant to the integration of social cognition, cognitive development and social development (see [63] for an argument concerning the integration of social and cognitive development research).

3. Of course, we expect that influences can be bidirectional, with social cognition providing insight into optimal developmental approaches, though this is not our focus here.

\section{ACKNOWLEDGEMENTS}

The authors wish to thank Carol Dweck, Wendy Berry Mendes, and Daniel Wegner for comments on an earlier draft and the Beinecke Scholarship and NSF Graduate Research Fellowship Program for funding.

\section{REFERENCES}

[1] Buldain RW, Crano WD, Wegner DM. Effects of age of actor and observer on the moral judgments of children. J Genet Psychol 1982; 14: 261-70.

[2] Fazio RH. On the self-perception explanation of the overjustification effect: The role of the salience of initial attitude. J Exp Soc Psychol 1981; 17: 417-26.

[3] Higgins ET, Bryant SL. Consensus information and fundamental attribution error: The role of development and in-group versus outgroup knowledge. J Pers Soc Psychol 1982; 43: 889-900.
[4] Lepper MR, Greene D, Nisbett RE. Undermining children's intrinsic interest with extrinsic reward: A test of the 'overjustification' hypothesis. J Pers Soc Psychol 1973; 28: 129-37.

[5] Pomerantz EM, Newman LS. Looking in on the children: Using developmental psychology as a tool for hypothesis testing and model building in social psychology. Pers Soc Psychol Rev 2000; 4: 300-16.

[6] Ruble DN, Goodnow JJ. Social development. In: Gilbert DT, Fiske ST, Lindzey G, Eds. The Handbook of Social Psychology. Boston: McGraw-Hill 1998; Vol. 2: pp. 741-87.

[7] Piaget J, Inhelder B. The Psychology of the Child. New York: Basic Books 1962.

[8] Carey S. Conceptual Change in Childhood. Cambridge, MA: MIT Press 1985.

[9] Fazio RH, Eiser JR, Shook NJ. Attitude formation through exploration: Valence asymmetries. J Pers Soc Psychol 2004; 87: 293-311.

[10] Sherman JW. Development and mental representation of stereotypes. J Pers Soc Psychol 996; 70:1126-41.

[11] Gregg AP, Seibt B, Banaji MR. Easier done than undone: Asymmetry in the malleability of implicit preferences. J Pers Soc Psychol 2006; 90: 1-20.

[12] Spelke ES. Core knowledge. Am Psychol 2000; 55: 1233-43.

[13] Carey S, Spelke ES. Science and core knowledge. Philos Sci 1996; 63: 515-33.

[14] Dehaene S, Changeux JP. Development of elementary numerical abilities: A neuronal model. J Cognit Neurosci 1993; 5: 390-407.

[15] Wynn K. Addition and subtraction by human infants. Nature 1992; 358: 749-50.

[16] Baillargeon R. Infants' physical world. Cur Dir Psychol Sci 2004; 13: 89-94.

[17] Gergel G, Nadasdy Z, Csibra G, Biro S. Taking the intentional stance at 12 months of age. Cognition 1995; 56: 165-93.

[18] Johnson SC, Booth A, O'Hearn K. Inferring the goals of a nonhuman agent. Cognit Dev 2001; 16: 637-56.

[19] Woodward AL. Infant selectively encode the goal object of an actor's reach. Cognition 1998; 69: 1-34.

[20] Le Corre M, Van de Walle G, Brannon EM, Carey S. Re-visiting the competence/performance debate in the acquisition of the counting principles. Cognit Psychol 2006; 52: 130-69.

[21] Gordon P. Numerical cognition without words: Evidence from Amazonia. Science 2004; 306: 496-9.

[22] Wellman HM. The Child's Theory of Mind. Cambridge, MA: MIT Press 1990.

[23] Uller C, Hauser M, Carey S. Spontaneous representation of number in cotton-top tamarins (Saguinus oedipus). J Comp Psychol 2001; 115: 248-57.

[24] Pica P, Lerner C, Izard V, Dehaene S. Exact and approximate arithmetic in an Amazonian Indigene Group. Science 2004; 306: 499-503.

[25] Hespos SJ, Spelke ES. Conceptual precursors to language. Nature 2004; 430: 453-6.

[26] Choi S, McDonough L, Bowerman M, Mandler JM. Early sensitivity to language-specific spatial categories in English and Korean. Cognit Dev 1999; 14: 241-68.

[27] Dehaene S. The Number Sense: How Mathematical Knowledge Is Embedded in Our Brains. New York: Oxford University Press 1997.

[28] Griffin S, Case R, Siegler R. Rightstart: Providing the central conceptual prerequisites for first formal learning of arithmetic to students at-risk for school failure. In: McGilly K, Ed. Classroom lessons: Integrating cognitive theory and classroom practice. Cambridge, MA: Bradford Books MIT Press 1994; pp. 24-49.

[29] Borstelmann LJ. Commentary on insights on the child development movement in the United States. Monogr Soc Res Child 1975; 40.

[30] Flavell JH. Theory-of-mind development: Retrospect and prospect. Merrill Palmer Quart 2004; 50: 274-90.

[31] Royzman EB, Cassidy KW, Baron J. 'I know, you know': Epistemic egocentrism in children and adults. Rev Gen Psychol 2003; 7: 38-65.

[32] Epley N, Morewedge CK, Keysar B. Perspective taking in children and adults: Equivalent egocentrism but differential correction. J Exp Soc Psychol 2004; 40: 760-8.

[33] Atran S. The Cognitive Foundations of Natural History: Towards an Anthropology of Science. New York: Cambridge University Press 1990. 
[34] Gil-White FJ. Are ethnic groups biological 'species' to the human brain? Curr Anthropol 2001; 42: 515-54.

[35] Olson KR, Banaji MR, Dweck CS, Spelke ES. Children's bias against lucky vs. unlucky people and their social groups. Psychol Sci 2006; 17: 845-6.

[36] Olson KR, Dunham Y, Dweck CS, Spelke ES, Banaji MR. Judgments of the lucky across development and culture. J Pers Soc Psychol 2008; 94: 757-76.

[37] Smith ER, DeCoster J. Dual-process models in social and cognitive psychology: Conceptual integration and links to underlying memory systems. Pers Soc Psychol Rev 2000; 4: 108-31.

[38] Devine PG. Stereotypes and prejudice: Their automatic and controlled components. J Pers Soc Psychol 989; 56: 5-18.

[39] Greenwald AG, Banaji MR. Implicit social cognition: Attitudes, self-esteem, and stereotypes. Psychol Rev 1995; 102: 4-27.

[40] Klaczynski PA, Cottrell JM. A dual-process approach to cognitive development: The case of children's understand of sunk cost decisions. Think Reason 2004; 10: 147-74.

[41] Rudman LA. Sources of implicit attitudes. Curr Dir Psychol Sci 2004; 13: 79-82.

[42] Rudman LA, Phelan JE, Heppen J. Developmental sources of implicit attitudes. Pers Soc Psychol B 2007; 33: 1700-13.

[43] Bargh JA, Chaiken S, Govender R, Pratto F. The generality of the automatic attitude activation effect. J Pers Soc Psychol 1992; 62: 893-912.

[44] Greenwald AG, Pickrell JE, Farnham SD. Implicit partisanship: Taking sides for no reason. J Pers Soc Psychol 2002; 83: 367-79.

[45] Baron AS, Banaji MR. The development of implicit attitudes: Evidence of race evaluations from ages 6 and 10 and adulthood. Psychol Sci 2006; 17: 53-8.

[46] Dunham Y, Baron AS, Banaji MR. From American city to Japanese village: A Cross-cultural investigation of implicit race attitudes. Child Dev 2006; 77: 1268-81.

[47] Dunham Y, Baron AS, Banaji MR. Children and social groups: A developmental analysis of implicit consistency in HispanicAmericans. Self Identity 2007; 6: 238-55.

[48] Rutland A, Cameron L, Milne A, McGeorge P. Social norms and self-presentation: Children's implicit and explicit intergroup attitudes. Child Dev 2005; 76: 451-66.
[49] Dunham Y, Banaji MR. Angry=Black or Angry=Outgroup? Research presentation. Available at faculty1.ucmerced.edu/ydunham.

[50] Markus HR, Kitayama S. Culture and the self: Implications for cognition, emotion, and motivation. Psychol Rev 1991; 98: 224-53.

[51] Nisbett RE. The geography of thought: How Asians and Westerners think differently.... and why. New York: Free Press 2003.

[52] Ekman P. Basic emotions. In: Dalgleish T, Power MJ, Eds. Handbook of cognition and emotion. New York: John Wiley \& Sons 1999.

[53] Russell JA, Bullock M. On the dimensions preschoolers use to interpret facial expressions of emotion. Dev Psychol 1986; 22: $97-$ 102.

[54] Russell JA, Widen SC. A label superiority effect in children's categorization of facial expressions. Soc Dev 2002; 11: 30-52.

[55] Harris PL. Children and emotion: The development of psychological understanding. Cambridge, MA: Basil Blackwell 1989.

[56] Field TM, Woodson R, Greenberg R, Cohen D. Discrimination and imitation of facial expressions by neonates. Science $1982 ; 218$ : $179-81$.

[57] Izard CE. Innate and universal facial expressions: Evidence from developmental and cross-cultural research. Psychol Bull 1994; 115: 288-99.

[58] Tracy JL, Robins RW, Lagattuta KH. Can children recognize pride? Emotion 2005; 5: 251-7.

[59] Izard CE, Fantauzzo CA, Castle JM, Haynes OM, Rayias MF Putnam PH. The ontogeny and significance of infants' facial expressions in the first nine months of life. Dev Psychol 1995; 31 : 997-1013.

[60] Field TM, Woodson R, Cohen D, Greenberg R, Garcia R, Collins $\mathrm{K}$. Discrimination and imitation of facial expressions by term and preterm neonates. Infant Behav Dev 1983; 6: 485-9.

[61] Greenwald AG, McGhee DE, Schwartz JLK. Measuring individual differences in implicit cognition: The implicit association test. J Pers Soc Psychol 1998; 74: 1464-80.

[62] Dweck CS, London B. The role of mental representation in social development. Merrill Palmer Quart 2004; 50: 428-44.

[63] Olson KR, Dweck CS. A blueprint for social cognitive development. Perspect Psychol Sci 2008; 3: 193-202.

(C) Dunham and Olson; Licensee Bentham Open.

This is an open access article licensed under the terms of the Creative Commons Attribution Non-Commercial License (http://creativecommons.org/licenses/ by-nc/3.0/) which permits unrestricted, non-commercial use, distribution and reproduction in any medium, provided the work is properly cited. 